$2-2013$

\title{
Mission Accomplished: A Reply to Reuveny and Keshk
}

\author{
Cullen F. Goenner \\ University of North Dakota, cgoenner@business.und.edu
}

How does access to this work benefit you? Let us know!

Follow this and additional works at: https://commons.und.edu/ef-fac

Part of the Economics Commons

\section{Recommended Citation}

Cullen F. Goenner. "Mission Accomplished: A Reply to Reuveny and Keshk" (2013). Economics \& Finance Faculty Publications. 10.

https://commons.und.edu/ef-fac/10

This Article is brought to you for free and open access by the Department of Economics \& Finance at UND Scholarly Commons. It has been accepted for inclusion in Economics \& Finance Faculty Publications by an authorized administrator of UND Scholarly Commons. For more information, please contact und.commons@library.und.edu. 
Mission Accomplished: A Reply to Reuveny and Keshk

Forthcoming: Conflict Management and Peace Science

Cullen F. Goenner

Department of Economics

293Centennial Drive Stop 8369

University of North Dakota

Grand Forks, ND 58202

cullen.goenner@und.edu

701-777-3353

\begin{abstract}
:
Reuveny and Keshk (2013) argue the econometric techniques used by Goenner (2011) to test and control for endogeneity, when estimating the relationship between trade and conflict lack substance. Both sets of authors propose use of instrumental variable methods, which are known by econometricians to be the natural remedy to estimation with potentially endogenous regressors. Where Goenner (2011) and Reuveny and Keshk (2013) agree is that theory should guide variable selection and the model's specification. Yet they differ in that while econometric tests cannot replace theory, one should not trust the appropriateness of the model's specification based on theory alone, one should also verify. Otherwise as Goenner (2011) notes, attempts to control for endogeneity may fail.
\end{abstract}

\title{
Introduction
}

Reuveny and Keshk (2013) operate under the premise that trade is an endogenous regressor in conflict models and should be controlled for to ensure the consistency of one's estimates. It seems logical that prior to finding a solution to a presumed problem, one should verify its existence. Econometric tests exist to determine whether endogeneity is a concern, as endogeneity may not be found in every specification of trade and conflict. If endogeneity exists, it also makes sense to utilize techniques that eliminate the problem and do not cause others. Goenner (2011) tests and finds that endogeneity can be an issue in model specifications of trade and conflict. Further he emphasizes a need to choose instruments, which replace the endogenous regressor, that are empirically shown to be relevant and exogenous. He argues failing to do so 
can result in estimates that are worse than those ignoring endogeneity entirely. Reuveny and Keshk (2013: ????) find such warnings on the choice of instruments to be "merely alarmist, lacking substance and veracity." The presence of endogeneity and use of weak or endogenous instruments is a real threat to the consistency of the results from conflict model specifications estimated using instrumental variables methods. Econometric tests can provide substance by verifying whether the threat is real and whether the steps we take to eliminate a realized threat are successful. Trusting our instruments to be valid, when they are not, will not eliminate the effects of endogeneity in our empirical estimates and will result in incorrect inferences.

\section{Endogeneity Concerns}

In standard OLS regression and Logistic/Probit regression models we assume the regressors are uncorrelated with the error term. If a variable is correlated with the error term it is said to be endogenous. Estimating a model with an endogenous regressor results in estimates that are inconsistent, which is to say our estimates do not converge to the true values with large sample sizes and thus our results are unreliable. Omitted variables, errors in variable measurement, and simultaneous causality are all potential sources of correlation between the regressors and error term, which is noted by Reuveny and Keshk (2013). Reuveny and Keshk (2013) suggest this correlation is due to simultaneity between trade and conflict, yet another possibility is endogeneity may be due to an unobserved factor that influences both trade and conflict. This factor, could for example capture dyadic interests, and is unable to be measured. It is not hard to imagine that interests would play a role in determining both trade and conflict. Failure to account for this could result in endogeneity and lead to inconsistent results as well. The tests identified by Goenner (2011), while useful for testing for the presence of endogeneity in a given specification, are unable to identify whether the cause is due to simultaneity or omitted variables. 
The key as noted by Stock and Watson (2003: 332) is: "Whatever the source of the correlation between $\mathrm{X}$ and $\mathrm{u}$, if there is a valid instrumental variable, $\mathrm{Z}$, then the effect on $\mathrm{Y}$ of a unit change in X can be estimated using the instrumental variables estimator."

Reuveny and Keshk (2013) argue testing for endogeneity is unnecessary, as endogeneity is inevitable in trade and conflict specifications. Let's assume endogeneity is shown to exist, and also assume is due to simultaneity. The question is how one proceeds. Goenner (2011) suggests you use a single equation approach, identifying relevant and exogenous variables to take the place of the endogenous regressor(s), whereas Reuveny and Keshk (2013) would have you instead specify a system of equations for each endogenous regressor, where estimation depends on certain exclusion restrictions. Both methods are forms of instrumental variables (IV) estimators, in fact as Greene (2008: 373) notes the various estimators that have been developed for simultaneous-equations models are all IV estimators. They differ in the choice of instruments and in whether the equations are estimated one at a time or jointly." This latter distinction identifies the models as limited or full information methods. The estimation techniques used by Goenner (2011) and Keshk, Pollins, and Reuveny (2004) are limited information methods, where the real difference is in their choice of instruments. ${ }^{1}$

The choice of instruments needs to be motivated by theory, as theory can help to identify potential instruments that influence the endogenous regressor(s) and do not influence the dependent variable. Reuveny and Keshk (2013) state that Goenner (2011) "arbitrarily" chose the instruments used in his analysis and suggest that the results thereby cannot be trusted. The Heckshcher-Ohlin theory of trade guided the selection of asymmetry in factor endowments as

\footnotetext{
${ }^{1}$ Keshk, Pollins, and Reuveny (2004) utilize two stage estimation techniques (Maddala, 1986) to estimate their trade and conflict specifications, whereas Goenner (2011) utilizes LIML to estimate the trade equation and a two stage method to estimate the conflict equation.
} 
influencing trade and potentially not influencing conflict. As noted, it is a challenge to identify instruments that are both relevant and exogenous. The important aspect shown by Goenner (2011) is that the instruments he uses are theoretically and empirically relevant and exogenous. Theory guided the choice of instruments, yet testing is equally important, otherwise our estimates will remain inconsistent in the presence of weak or endogenous instruments.

Reuveny and Keshk (2013) correctly highlight that the instruments they use in place of trade are the variables included in their trade specification and those left out of the conflict equation. Keshk, Pollins, and Reuveny (2004) and Keshk, Reuveny, and Pollins (2010) both for example exclude contiguity from their trade model specification and include it in their conflict model, while conversely they include distance in their trade model specification and exclude it from their conflict model. This implies contiguity is an instrument for conflict and distance is an instrument for trade. Do we really believe that contiguity and distance do not both influence trade and conflict independently? ${ }^{2}$ If they do, then their instruments (contiguity and distance) are no longer uncorrelated with the error terms and estimates using Reuveny and Keshk's methods are inconsistent. When Goenner (2011) drops distance from his conflict specification, the omitted variable creates correlation between Goenner's (2011) instruments and the error term which results in instruments that are no longer exogenous. The finding trade does not significantly reduce conflict, is not an indictment of his earlier findings, but instead again emphasizes the importance to test for the appropriateness of the instruments prior to drawing conclusions based on one's estimates. One should not base inferences on estimates that are shown to be inconsistent.

\footnotetext{
${ }^{2}$ Distance serves as a proxy for transportation costs in the gravity model as noted by Reuveny and Keshk (2013). Contiguity though influences the manner in which trade takes place. Countries that are contiguous are able to exchange products without crossing borders of other countries, which facilitates exchange by reducing transportation costs. Similarly distance is likely to proxy for interests and thus influences conflict.
} 
The clear advantage of paying attention to the estimation of one equation rather than a system of equations is advanced by Reuveny and Keshk's (2013) discussion of the inherent complexity of the world. Attempting to specify a complete model, while noble, may lead to more issues, when variables in the system are assumed to be exogenous and are in fact not. In such a case Greene (2008: 387) notes “this specification error would be quite serious." Goenner (2011) does not presume the equations estimated are necessarily misspecified, but understands the complexity inferred by Reuveny and Keshk (2013), and does not presume to know the source of endogeneity, when shown to exist. The point of using instrumental variables methods is not to use the most instruments, but to use relevant and exogenous instruments to control for endogeneity. Otherwise the estimates remain inconsistent, which is the case when endogeneity is ignored. Reuveny and Keshk (2013) argue endogeneity tests are not applicable to macroeconomic studies and thus other macro issues, such as trade and conflict. To support their view they quote Greene (2008: 357), which they infer indicates endogeneity tests are not applicable to macroeconomic studies, yet a few pages later Greene (2008: 388) uses just such a test applied to the macroeconomic model referenced earlier. Endogeneity tests are more common to microeconomic studies, where demand and supply create a natural system, but there is nothing theoretical or empirical preventing their use with macro studies.

\section{Specification Concerns}

Reuveny and Keshk (2013) further question the choice of exogenous variables used in Goenner's (2011) specifications. Theory should guide the choice of variables, yet as Goenner (2004) has previously made clear, theory does not always suggest how to measure variables of theoretical interest. The variables used by Goenner (2011) are those typical to most studies of trade and conflict. One such example is the use of the logged product of each country's population and 
GDP in the trade specification. Reuveny and Keshk (2013: ????) find Goenner's (2011) choice to be "atheoretical" and would prefer each country's logged GDP and population be used separately. This is a rare case where trade theory (Helpman and Krugman, 1985) has actually suggested the product of GDPs be used. Given it does not make theoretical sense for the empirical effect of GDP or population to vary by whether a country in a pair is labeled as a or b, the estimated coefficients on the separate terms should be the same. ${ }^{3}$ Thus from the mathematical and theoretical standpoint the log of the product of two numbers is the same as the sum of the logged values, so using either set of variables is appropriate. To avoid empirical complications, one can constrain the values to be equal, given theory, and thus use the product of the values as was done by Goenner (2011) and which is common in the literature. ${ }^{4}$ One could take this even a step further (Anderson and van Wincoop, 2003) and impose unitary income elasticities, which are found in some theory based gravity models. This would constrain the parameters on the trading partners' GDPs to both be equal to one. Theoretical trade models offer little additional guidance on how to introduce other forms of resistance to the specification. The functional form chosen for these variables, as for most cases, is at the discretion of the researcher. There is nothing to suggest a need to use a logged value of regime type any more so than for the other indicator variables (allies, contiguity) capturing resistance.

For the "better" applied researchers develop new tests and estimation methods whose purpose is to help improve our understanding of empirical relationships. Statistical tests are a source of information, not to be overlooked, which we can use to support or refute our prior beliefs based on their strengths. What is "worse" is to presume that theory can provide a definitive guide to the appropriate model's specification, such that testing is unnecessary. We

\footnotetext{
${ }^{3}$ Linnemann (1966: 86-87) provides further discussion on this point.

${ }^{4}$ See for example Frankel (1997) and Rose (2004).
} 
can agree that such methods should be used with caution, as we must also recognize their limitations.

\section{References}

Anderson, James E., and van Wincoop, E., 2003. Gravity with Gravitas: A Solution to the Border Puzzle. American Economic Review 93 (1): 170-192.

Frankel, Jeffrey A., 1997. Regional Trading Blocs in the World Economic System. Washington DC: Institute for International Economics.

Goenner, Cullen F., 2004. 'Uncertainty of the Liberal Peace', Journal of Peace Research 41(5): 589-605.

Goenner, Cullen F., 2011. 'Simultaneity between trade and conflict: Endogenous Instruments of Mass Destruction', Conflict Management and Peace Science, 28(5): 459-477.

Greene, William H., 2008. Econometric Analysis. New York: Pearson.

Helpman, Elhanan, and Krugman, Paul, 1985. Market Structure and Foreign Trade. Cambridge, MA: MIT Press.

Keshk, Omar M. G., Pollins, Brian M., and Reuveny, Rafael, 2004. 'Trade Still Follows the Flag: The Primacy of Politics in a Simultaneous Model of Interdependence and Armed Conflict', Journal of Politics 66(4): 1155-1179.

Keshk, Omar M. G., Reuveny, Rafael, and Pollins, Brian M., 2010. 'Trade and Conflict: Proximity, Country Size, and Measures', Conflict Management and Peace Science, 27(1):3-27.

Linnemann, Hans, 1966. An Econometric Study of International Trade Flows. Amsterdam: North-Holland.

Maddala, G. S., 1983. Limited-Dependent and Qualitative Variables in Econometrics. Cambridge, UK: Cambridge University Press.

Reuveny, Rafael and Keshk, Omar M. G., 2013. "Reconsidering Trade and Conflict Simultaneity: The Risk of Emphasizing Technique over Substance”, Conflict Management and Peace Science, ???? 
Rose, Andrew K., 2004. 'Do We Really Know That the WTO Increases Trade?', American Economic Review 94(1): 98-114.

Stock, James H. and Watson, Mark W., 2003. Introduction to Econometrics. New York: Addison Wesley. 